\title{
A nanobody-based nuclear imaging tracer targeting dipeptidyl peptidase 6 to determine the mass of human beta cell grafts in mice
}

\author{
Stéphane Demine ${ }^{1}$ (D) $\cdot$ Rita Garcia Ribeiro ${ }^{2} \cdot$ Julien Thevenet $^{3} \cdot$ Lorella Marselli $^{4} \cdot$ Piero Marchetti $^{4} \cdot$ François Pattou $^{3}$. \\ Julie Kerr-Conte ${ }^{3} \cdot$ Nick Devoogdt $^{2} \cdot$ Decio L. Eizirik $^{1}$
}

Received: 24 July 2019 / Accepted: 30 October 2019/Published online: 23 December 2019

(C) Springer-Verlag GmbH Germany, part of Springer Nature 2019

\begin{abstract}
Aims/hypothesis Type 1 diabetes is characterised by a progressive decline in beta cell mass. This is also observed following implantation of pancreatic islet allografts, but there is no reliable information regarding the time course of beta cell loss. This is due to the limited availability of non-invasive pancreatic islet imaging techniques. We have previously described that dipeptidyl peptidase 6 (DPP6) is an alpha and beta cell-specific biomarker, and developed a camelid antibody (nanobody '4hD29') against it. We demonstrated the possibility to detect DPP6-expressing cells by single-photon emission computed tomography (SPECT)/ computed tomography (CT), but the correlation between the number of cells grafted and the SPECT signal was not assessed. Here, we investigate whether the $4 \mathrm{hD} 29$ nanobody allows us to detect different amounts of human pancreatic islets implanted into immune-deficient mice. In addition, we also describe the adaptation of the probe for use with positron emission tomography (PET). Methods DPP6 expression was assessed in human samples using tissue arrays and immunohistochemistry. The effect of the 4hD29 nanobody on cell death and glucose-stimulated insulin secretion was measured in EndoC- $\beta \mathrm{H} 1$ cells and in human islets using Hoechst/ propidium iodide staining and an anti-insulin ELISA, respectively. We performed in vivo SPECT imaging on severe combined immunodeficient (SCID) mice transplanted with different amounts of EndoC- $\beta \mathrm{H} 1$ cells $\left(2 \times 10^{6}, 5 \times 10^{6}\right.$ and $10 \times 10^{6}$ cells), human islets (1000 and 3000) or pancreatic exocrine tissue using ${ }^{99 \mathrm{~m}} \mathrm{Tc}$-labelled $4 \mathrm{hD} 29$ nanobody. This DPP6 nanobody was also conjugated to $N$-chlorosuccinimide (NCS)-1,4,7-triazacyclononane-1,4,7-triacetic acid (NOTA), radiolabelled with either ${ }^{67} \mathrm{Ga}$ (SPECT) or ${ }^{68} \mathrm{Ga}$ (PET) and used in a proof-of-principle experiment to detect DPP6-expressing cells (Kelly neuroblastoma) grafted in SCID mice.

Results The DPP6 protein is mainly expressed in pancreatic islets. Importantly, the anti-DPP6 nanobody $4 \mathrm{hD} 29$ allows noninvasive detection of high amounts of EndoC- $\beta \mathrm{H} 1$ cells or human islets grafted in immunodeficient mice. This suggests that the probe must be further improved to detect lower numbers of islet cells. The $4 \mathrm{hD} 29$ nanobody neither affected beta cell viability nor altered insulin secretion in EndoC- $\beta \mathrm{H} 1$ cells and human islets. The conversion of $4 \mathrm{hD} 29$ nanobody into a PET probe was successful and did not alter its specificity.

Conclusions/interpretation These findings suggest that the anti-DPP6 4hD29 nanobody may become a useful tool for the quantification of human islet grafts in mice and, pending future development, islet mass in individuals with diabetes.
\end{abstract}

Keywords Human islet imaging $\cdot$ Pancreatic beta cell imaging $\cdot$ Pancreatic beta cells $\cdot$ PET $\cdot$ SPECT $\cdot$ Type 1 diabetes

Stéphane Demine and Rita Garcia Ribeiro are joint first authors. Julie Kerr-Conte, Nick Devoogdt and Decio L. Eizirik are joint senior authors.

Electronic supplementary material The online version of this article (https://doi.org/10.1007/s00125-019-05068-5) contains peer-reviewed but unedited supplementary material, which is available to authorised users.

Stéphane Demine

stephane.demine@ulb.ac.be

1 ULB Center for Diabetes Research and Welbio, Medical Faculty, Université Libre de Bruxelles (ULB), Route de Lennik 808-CP618, 1070 Brussels, Belgium
2 In Vivo Cellular and Molecular Imaging Laboratory (ICMI), Vrije Universiteit Brussel (VUB), Brussels, Belgium

3 European Genomic Institute for Diabetes, UMR 1190 Translational Research for Diabetes, Inserm, CHU Lille, University of Lille, Lille, France

4 Department of Clinical and Experimental Medicine, University of Pisa, Pisa, Italy 


\section{Research in context}

\section{What is already known about this subject?}

- Type 1 diabetes is characterised by a progressive decline in beta cell mass. A similar phenomenon also happens following pancreatic islet allografts; however, there is no reliable information regarding the time course of beta cell loss. This is due to the limited availability of non-invasive pancreatic islet imaging techniques

- We previously identified dipeptidyl peptidase 6 (DPP6) as a new alpha and beta cell-specific biomarker and developed a nanobody-based imaging probe targeting DPP6 ('4hD29')

\section{What is the key question?}

- Can the anti-DPP6 nanobody 4hD29 be used to detect and quantify human beta cells grafted in mice?

\section{What are the new findings?}

- The single-photon emission computed tomography (SPECT) signal emitted by ${ }^{99 m} \mathrm{mc}$-labelled $4 \mathrm{hD} 29$ is specific to EndoC- $\beta \mathrm{H} 1$ cells or primary human islets transplanted in severe combined immunodeficient (SCID) mice, and can be used to visualise high numbers of cells/islets

- The 4hD29 nanobody has no deleterious effects on cell viability or glucose-stimulated insulin secretion in EndoC$\beta \mathrm{H} 1$ cells or human islets

- The probe was successfully adapted to positron emission tomography (PET)/computed tomography (CT) by conjugation to $\mathrm{N}$-chlorosuccinimide (NCS)-1,4,7-triazacyclononane-1,4,7-triacetic acid (NOTA). This modification did not alter its specificity. Preliminary experiments using Kelly cells also showed that this technique has very good sensitivity and could be used in the future to quantify grafts

\section{How might this impact on clinical practice in the foreseeable future?}

- Pending further validation and improvements in sensitivity, the 4hD29 nanobody may become a useful tool for the quantification of islet cell mass in humans

$\begin{array}{ll}\text { Abbreviations } \\ \text { CT } & \text { Computed tomography } \\ \text { DPP6 } & \text { Dipeptidyl peptidase 6 } \\ \text { \%IA } & \text { Per cent of injected activity } \\ \text { IEQ } & \text { Islet equivalents } \\ \text { iTLC } & \text { Instant thin-layer chromatography } \\ \text { NCS } & \text { N-chlorosuccinimide } \\ \text { NH } 4 \text { OAc } & \text { Ammonium acetate } \\ \text { NOTA } & \text { 1,4,7-Triazacyclononane-1,4,7-triacetic acid } \\ \text { PET } & \text { Positron emission tomography } \\ \text { ROI } & \text { Region of interest } \\ \text { RPKM } & \text { Reads per kb per million mapped reads } \\ \text { SCID } & \text { Severe combined immunodeficient (mice) } \\ \text { SPECT } & \text { Single-photon emission computed tomography }\end{array}$

\section{Introduction}

The non-invasive quantification of beta cell mass in individuals with diabetes or following islet transplantation remains a major challenge [1]. In recent years, several beta cell imaging probes have been developed [2]. The most advanced probes are probably the exendin- 4 derivatives targeting the glucagon-like peptide
1 (GLP-1) receptor [3]. However, it remains to be shown whether they allow discrimination between different degrees of beta cell loss in human disease.

Ongoing attempts for beta cell/islet imaging rely on 'chemical resolution', i.e. the detection of positron emission tomography (PET) or single-photon emission computed tomography (SPECT) signals that are specifically derived from beta cells or endocrine islet cells, with very little signal from the exocrine pancreas or closely located abdominal tissues [1].

By using a functional genomics approach, we previously identified dipeptidyl peptidase 6 (DPP6) as a human beta and alpha cell-specific biomarker [4]. Based on these findings, we generated a camelid single-domain antibody (nanobody)-based probe targeting the DPP6 protein [4]. This nanobody, named '4hD29', recognises the human but not rodent, DPP6 protein and, using imaging techniques, allowed its detection in human DPP6-expressing cells [4], namely the neuroblastoma cancer cell line Kelly and the human immortalised insulin-producing beta cells EndoC- $\beta \mathrm{H} 1$, both implanted in severe combined immunodeficient (SCID) mice [4]. The specificity and the pharmacokinetic properties of the $4 \mathrm{hD} 29$ nanobody have been previously assessed [4].

In the present study, we evaluated whether this probe can be used to discriminate different amounts of EndoC- $\beta \mathrm{H} 1$ cells 
or primary human islets grafted into SCID mice. We also evaluated its potential toxicity to cultured human beta cells in vitro. Finally, we report the adaptation of the probe structure for PET imaging and determine probe specificity when used in PET.

\section{Methods}

\section{Human pancreatic islets and ethical information}

Human pancreases not suitable for clinical purposes were collected at the Endocrinology and Metabolism of Organ and Cellular Transplantation Unit of the Cisanello University Hospital in Pisa, Italy, and handled as previously reported [5]. Pancreases were also harvested, after consent for research, at the European Genomic Institute for Diabetes, Translational Research for Diabetes, University of Lille (Lille, France) from brain-deceased donors, as authorised by the French procurement agency (Agence de la BioMédecine), and islets were isolated. Human islets insufficient in number for transplantation were distributed for research only if research consent was granted by the European consortium for islet transplantation (ECIT). Human islet isolation and culture were performed in Lille (France), as previously described [6].

All methods using human pancreatic samples and mice were performed with the approval of the local Ethics committees of: the University of Pisa, Italy; Northern France (Comités d'éthique en expérimentation animale [CEEA] 75); the Vrije Universiteit Brussel (VUB), Belgium; or the Université Libre de Bruxelles (ULB), Belgium. Anonymised patient information is provided in the electronic supplementary material (ESM) Table 1.

\section{Immunohistochemistry}

Human tissue arrays were provided by the Center for Microscopy and Molecular Imaging (CMMI), Gosselies, Belgium. The tissue arrays were deparaffinised using consecutive solvent baths (xylene, $2 \times 3 \mathrm{~min} ; 100 \%$ ethanol, $2 \times 3 \mathrm{~min}$; $95 \%$ ethanol [vol./vol.], $3 \mathrm{~min} ; 70 \%$ ethanol [vol./vol.], $3 \mathrm{~min}$; 50\% ethanol [vol./vol.], $3 \mathrm{~min}$; distilled water, $2 \times 3 \mathrm{~min}$ ). An antigen retrieval step was performed by heating the slides for $20 \mathrm{~min}$ at $98^{\circ} \mathrm{C}$ in sodium citrate buffer $(10 \mathrm{mmol} / 1$ sodium citrate, $0.05 \%$ [vol./vol.] Tween$20 ; \mathrm{pH}$ 6.0). The arrays were then blocked for $1 \mathrm{~h}$ at room temperature in tris-buffered-saline buffer containing $10 \%$ normal goat serum (vol./vol.) and $1 \%$ bovine serum albumin (BSA) (wt/vol.) (Sigma, St Louis, MO, USA). Antibodies and conditions used for the immunodetection are detailed in ESM Table 2. Finally, the slides were mounted using Vectashield mounting medium containing
DAPI (Vector Laboratories, Peterborough, NH, USA) and analysed using a fluorescent microscope (Axiovert; Zeiss, Oberkochen, Germany).

\section{Cell culture and treatment}

The human beta cell line EndoC- $\beta \mathrm{H} 1$ (kindly provided by R. Scharfmann, University of Paris, Paris, France [7]) was cultured as described previously [8]. Human Kelly (pNB-1) neuroblastoma cells were obtained from the European Collection of Authenticated Cell Cultures (ECACC; catalogue no. 92110411; Salisbury, UK) and cultured as previously described [4]. Absence of mycoplasma infection was confirmed using the MycoAlert Mycoplasma Detection kit (Lonza, Basel, Switzerland). As indicated, some cells (EndoC- $\beta \mathrm{H} 1$ or human islets) were exposed to IFN $\gamma$ $(1000 \mathrm{U} / \mathrm{ml})$ and $\mathrm{IL}-1 \beta(50 \mathrm{U} / \mathrm{ml})$, and/or to increasing concentrations of either $4 \mathrm{hD} 29$ or control nanobody, for $24 \mathrm{~h}$. At this time point, the supernatant of human islets was used to determine insulin accumulation via an anti-human insulin ELISA (measurement range, 21-1388 pmol/1; Mercodia, Uppsala, Sweden). Insulin values were normalised for the protein content (expressed as $\mu \mathrm{g}$ of protein), as determined using a Bradford assay (BioRad, Hercules, CA, USA). Cell viability was assessed using Hoechst/propidium iodide staining and manual counting [9].

For evaluation of glucose-induced insulin secretion, EndoC- $\beta \mathrm{H} 1$ cells were preincubated for $24 \mathrm{~h}$ with culture medium containing $375 \mu \mathrm{g} / \mathrm{ml} 4 \mathrm{hD} 29$ or control nanobody. Untreated cells were used as control. Cells were then incubated in Krebs-Ringer buffer for $1 \mathrm{~h}$ and challenged with the same buffer containing $0 \mathrm{mmol} / \mathrm{l}$ or $20 \mathrm{mmol} / 1$ glucose or $20 \mathrm{mmol} / \mathrm{lglucose}+20 \mu \mathrm{mol} / \mathrm{l}$ forskolin. Supernatants and cell lysates were collected and insulin content was determined in each fraction using a human insulin ELISA kit (Mercodia, Uppsala, Sweden), as described previously [10]. Insulin values were normalised to protein content, as mentioned above.

\section{Transplantation of human islets, EndoC- $\beta \mathrm{H} 1$ cells or neuroblastoma Kelly cells into immunodeficient mice}

Six-week-old female SCID (CB17/Icr-Prkdc $c^{\text {scid }} / \mathrm{Rj}$ ) mice (Janvier, Le Genest-Saint-Isle, France) were selected for their tolerance regarding cell transplantation. SCID mice were housed in a specific pathogen-free (SPF) animal facility and transplanted with varying numbers of human insulin-producing EndoC- $\beta \mathrm{H} 1$ cells $\left(2 \times 10^{6}, 5 \times 10^{6}\right.$ and $10 \times 10^{6}$ ) in Matrigel-containing rubber rings, as previously described [4]. As a control, mice were also transplanted with rubber rings containing Matrigel only, as previously described [4]. The Kelly cells were transplanted 
subcutaneously in the same mouse model, as described before [4]. For human islet transplantation, 8-week-old female SCID (CB17/Icr-Prkdc ${ }^{\text {scid }} / \mathrm{Rj}$ ) mice were purchased from Charles River Laboratories (Saint-Germain-surl'Arbresle, France) and housed in a specific and opportunistic pathogen-free (SOPF) animal facility. Under general anaesthesia, the mice received a pancreatic graft under the skin in the scapular space (exocrine tissue, 1000 or 3000 islet equivalents [IEQ]). The mice were then followed for 4 weeks (human islets) or 12 weeks (EndoC- $\beta \mathrm{H} 1$ cells) and assessed for body weight, blood glucose levels (using the glucometer Accu-Chek Aviva; Roche, Basel, Switzerland) and human C-peptide circulating levels (UltraSensitive Human C-peptide ELISA Kit; measurement range, 5-280 pmol/l; Mercodia, Uppsala, Sweden). For further details of animal studies, please see ESM Methods.

\section{Radiolabelling procedures}

${ }^{99 m} \mathrm{Tc}$ labelling A volume corresponding to $50 \mu \mathrm{g}$ nanobody [4] in $1 \mathrm{mg} / \mathrm{ml}$ PBS (pH 7.4) was incubated with $500 \mu \mathrm{l}{ }^{99 \mathrm{~m}}$ Tc-tricarbonyl $( \pm 1 \mathrm{GBq})$ for $90 \mathrm{~min}$ at $50^{\circ} \mathrm{C}$. The radiochemical purity was determined via instant thin-layer chromatography (iTLC) on silica gel (Pall, Hoegaarden, Belgium) with acetone as the eluent. Prior to in vivo use, the radiolabelled tracers were purified via gel-filtration chromatography on Illustra NAP-5 desalting columns (GE Healthcare, Chicago, IL, USA), with elution in PBS-Tween (0.1\% [vol./vol.]; pH 7.4), according to the manufacturer's protocol. Finally, they were purified via passage through a $0.22 \mu \mathrm{m}$ polyvinylidene fluoride membrane filter (Merck Millipore, Burlington, VT, USA).

1,4,7-Triazacyclononane-1,4,7-triacetic acid coupling Prior to random coupling between the $4 \mathrm{hD} 29$ nanobody or control nanobody ('R3b23') and $N$-chlorosuccinimide (NCS)-1,4,7triazacyclononane-1,4,7-triacetic acid (NOTA), the nanobody (4hD29 or R3b23; $4 \mathrm{mg}$ in $4 \mathrm{ml} \mathrm{PBS}$ ) was concentrated using a Vivaspin tube (MWCO 5000; Sartorius, Göttingen, Germany) at $1006 \mathrm{~g}$ for $10 \mathrm{~min}$ at $15^{\circ} \mathrm{C}$, until a concentration of more than $2 \mathrm{mg} / \mathrm{ml}$ was reached. Next, the nanobody buffer was exchanged with carbonate buffer using a PD-10 desalting column (GE Healthcare). First, the column was preequilibrated with $25 \mathrm{ml}$ of $0.05 \mathrm{~mol} / 1$ carbonate buffer. Second, the nanobody sample $(3 \mathrm{mg}$ ) was topped up to $2.5 \mathrm{ml}$ with carbonate buffer and added to the column. Thereafter, the PD-10 column was eluted with $3.5 \mathrm{ml}(7 \times$ $0.5 \mathrm{ml}$ ) of carbonate buffer. The fractions with the highest concentrations of nanobody were added together and used in the subsequent steps. Next, NCS-NOTA was added for a nanobody:NCS-NOTA ratio of 1:20. The $\mathrm{pH}$ was adjusted to
8.5-8.7 to enable the reaction to take place. After a $2.5 \mathrm{~h}$ incubation at room temperature, $1 \mathrm{~mol} / 1 \mathrm{HCl}$ was added to stop the reaction. Third, the solution was purified by centrifugation in a Vivaspin tube at $1820 \mathrm{~g}$ for $6 \mathrm{~min}$ at $15^{\circ} \mathrm{C}$. The concentrated reaction mixture was collected by spinning the tube upside down at $528 \mathrm{~g}$ for $2 \mathrm{~min}$ at $15^{\circ} \mathrm{C}$. The mixture was then ready for size exclusion chromatography (SEC). For this purpose, an NGC liquid chromatography system was used (Bio-Rad, Temse, Belgium). A Superdex Peptide 10/300 GL column (GE Healthcare) was attached to the liquid chromatography system and the flow rate was set to $0.50 \mathrm{ml} / \mathrm{min}$ with elution in $0.1 \mathrm{~mol} / 1 \mathrm{NH}_{4} \mathrm{OAc}$. This separated the product of interest, namely the NCS-NOTA-coupled nanobodies. NCS-NOTAcoupled nanobodies were then radiolabelled with ${ }^{67} \mathrm{Ga}$ or ${ }^{68} \mathrm{Ga}$.

${ }^{67}$ Ga labelling $\left[{ }^{67} \mathrm{Ga}\right]$ citrate $( \pm 203.5 \mathrm{mBq}$; Mallinckrodt Nuclear Medicine, Mechelen, Belgium) was converted to $\left[{ }^{67} \mathrm{Ga}\right]$ chloride with a Sep-Pak C18 cartridge $(100 \mathrm{mg})$ (Waters, Herts, UK) by first applying $3 \mathrm{ml}$ of methanol for activation, followed by $6 \mathrm{ml}$ of metal-free water. The eluate solution was reapplied to the Sep-Pak Si cartridge and citrate ions were removed from the cartridge by washing it three times with $5 \mathrm{ml}$ metal-free water. Following this step, the cartridge was eluted with $300 \mu \mathrm{l}$ of $0.1 \mathrm{~mol} / \mathrm{l}$ metal-free $\mathrm{HCl}$. Next, $5 \mathrm{~mol} / \mathrm{l} \mathrm{NH}_{4} \mathrm{OAc}$ was added to the nanobody aliquot in $0.1 \mathrm{~mol} / 1 \mathrm{NH}_{4} \mathrm{OAc}(\mathrm{pH} 7)$ to reach an end concentration of $0.5 \mathrm{~mol} / 1 \mathrm{NH}_{4} \mathrm{OAc}$. Then, a $\left[{ }^{67} \mathrm{Ga}\right] \mathrm{GaCl}_{3}$ solution was added to the reaction mixture and incubated at room temperature for $10 \mathrm{~min}$. The radiolabelled nanobodies were subsequently purified by passing the solution through a NAP5 column (GE Healthcare) with injection buffer. The purified fraction was passed through a $0.22 \mu \mathrm{m}$ PVDF membrane filter, ready for in vivo use. iTLC was used to determine the radiochemical purity, with $0.1 \mathrm{~mol} / \mathrm{l}$ sodium citrate as eluent.

${ }^{68}$ Ga labelling A volume corresponding to $100 \mu \mathrm{g}$ of nanobody was added to $1 \mathrm{ml}$ of $\mathrm{NaOAc}$ and incubated with $1 \mathrm{ml}$ of ${ }^{68} \mathrm{Ga}\left( \pm 220 \mathrm{mBq}\right.$; Galli Eo ${ }^{68} \mathrm{Ge} /{ }^{68} \mathrm{Ga}$ generator; IRE ELiT, Fleurus, Belgium) for $10 \mathrm{~min}$ at room temperature. iTLC was used to determine the radiochemical purity, with $0.1 \mathrm{~mol} / 1$ sodium citrate as eluent. Further, the radiolabelled nanobodies were purified by passing the solution through a PD-10 desalting column with injection buffer. The fractions with the highest concentrations of nanobodies were added together and passed through a $0.22 \mu \mathrm{m}$ PVDF membrane filter.

\section{In vivo imaging and ex vivo biodistribution analysis of radiolabelled tracers}

All mice received 2.5\% (vol./vol.) isoflurane (Abbott, Wavre, Belgium) for general gas anaesthesia during tracer injections and SPECT/computed tomography (CT) imaging. Detailed information regarding the imaging of mice grafted with 
Fig. 1 Expression of DPP6 protein in different human organs. Tissue arrays were produced from tissue samples collected from five healthy individuals, including (a) liver, lung, prostate, spleen, kidney, white matter, intestine, cortex, stomach and (b) pancreas. Expression of insulin, glucagon and DPP6 was detected by either specific monoclonal or polyclonal antibodies and corresponding secondary antibodies conjugated to Alexa Fluor $488 \mathrm{~nm}$ (insulin, green), $546 \mathrm{~nm}$ (DPP6, red) or $647 \mathrm{~nm}$ (glucagon, orange). Nuclei counterstaining was performed using DAPI (blue).

Pictures were taken with an epifluorescence microscope (Zeiss Axiovert Imager A1) with either $(\mathbf{a}) \times 20$ (scale bar $=$ $100 \mu \mathrm{m})$ or $(\mathbf{b}) \times 40$ (scale bar $=$ $50 \mu \mathrm{m})$ magnification. The pictures shown are representative of the material from $n=5$ individual donors. White arrow indicates cells positive for DPP6 in the cortex. Gcg, glucagon; Ins, insulin; W. matter, white matter a
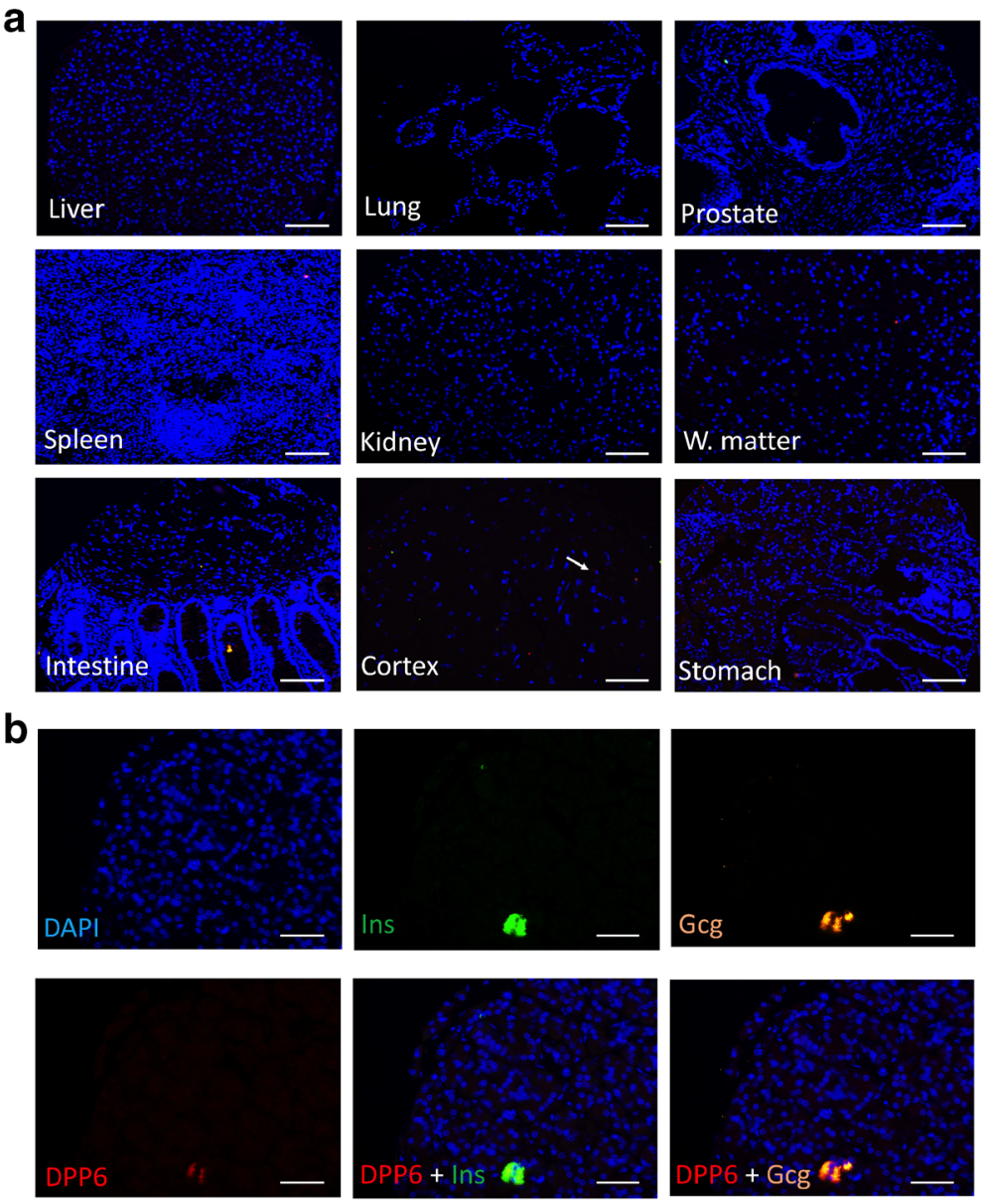

radiolabelled EndoC- $\beta \mathrm{H} 1$ cells, human islets or Kelly cells, including respective injected doses and specific radioactivity of the tracers, are shown in ESM Tables 3, 4 and 5.

SPECT/CT acquisitions were performed on a microSPECT/CT scanner $\left(V E C T o{ }^{+} \mathrm{CT}\right.$; MILabs, Utrecht, the Netherlands) with a $75 \mathrm{~mm}$ axial field-of-view and a $1.5 \mathrm{~mm}$ spatial resolution, $1 \mathrm{~mm}$ pinhole opening, $250 \mathrm{~mm}$ focal length and $47 \mathrm{~mm}$ radius of rotation. One hour after tracer injection, the animals were placed under general anaesthesia and images were acquired over $360^{\circ}$ in 50 projections of $18 \mathrm{~s}$, with the high photopeak window ranging from $225.60 \mathrm{keV}$ to $254.40 \mathrm{keV}$, and the scatter window from $206.40 \mathrm{keV}$ to $225.6090 \mathrm{keV}$. The acquired SPECT images were reconstructed into a $196 \times 196 \times 571$ matrix by a $3 \mathrm{D}$ maximum likelihood expectation maximisation algorithm (MILabs) using two iterations with four subsets and an isotropic voxel size of $0.2 \mathrm{~mm}$ that included attenuation and scatter correction. Each SPECT scan was preceded by a 1.48 min CT scan using the following acquisition parameters: tube voltage, $55 \mathrm{kV}$; tube current, $615 \mu \mathrm{A}$; exposure time, $240 \mathrm{~ms}$; rotation angle, $1.98^{\circ}$; and $\mathrm{Al}$ filter, $0.5 \mathrm{~mm}$. CT images were analytically reconstructed using the filtered back projection reconstruction software of the scanner (NRecon, Skyscan; Bruker, Billerica, MA, USA) into a $196 \times 196 \times 571$ matrix with $167 \mu \mathrm{m}$ isotropic voxel size. Images were analysed using AMIDE 1.0.4 (a medical image data analysis tool; http://amide.sourceforge.net/). For SPECT image quantification, $75.4 \mathrm{~mm}^{3}$ (for EndoC- $\beta \mathrm{H} 1$ grafts and respective controls) or $250 \mathrm{~mm}^{3}$-sized (for human islet grafts and respective controls) regions of interest (ROIs) were drawn around each implantation area or in control tissue on the co-registered SPECT and CT images, and activities in the ROIs were quantified. Pictures were analysed with AMIDE software [11], scaled for the injected dose and the raw data (obtained as counts) were converted to $\mathrm{mCi} / \mathrm{ml}$ and to $\mathrm{Bq} / \mathrm{ml}\left(1 \mathrm{mCi}=3.7 \times 10^{7} \mathrm{~Bq}\right)$. To calculate per cent of injected activity (\%IA), we used the following formula:

$\% \mathrm{IA} / \mathrm{mm}^{3}=\frac{\left(\text { Mean uptake in ROI } \times\left(\frac{\text { Size }}{1000}\right)\right)}{\text { Injected dose }} \times 100$

With: mean uptake in ROI in $\mathrm{Bq} / \mathrm{ml}$; size in $\mathrm{mm}^{3}$; injected dose in $\mathrm{Bq}$; and per cent injected dose expressed as $\% \mathrm{IA} / \mathrm{mm}^{3}$. 

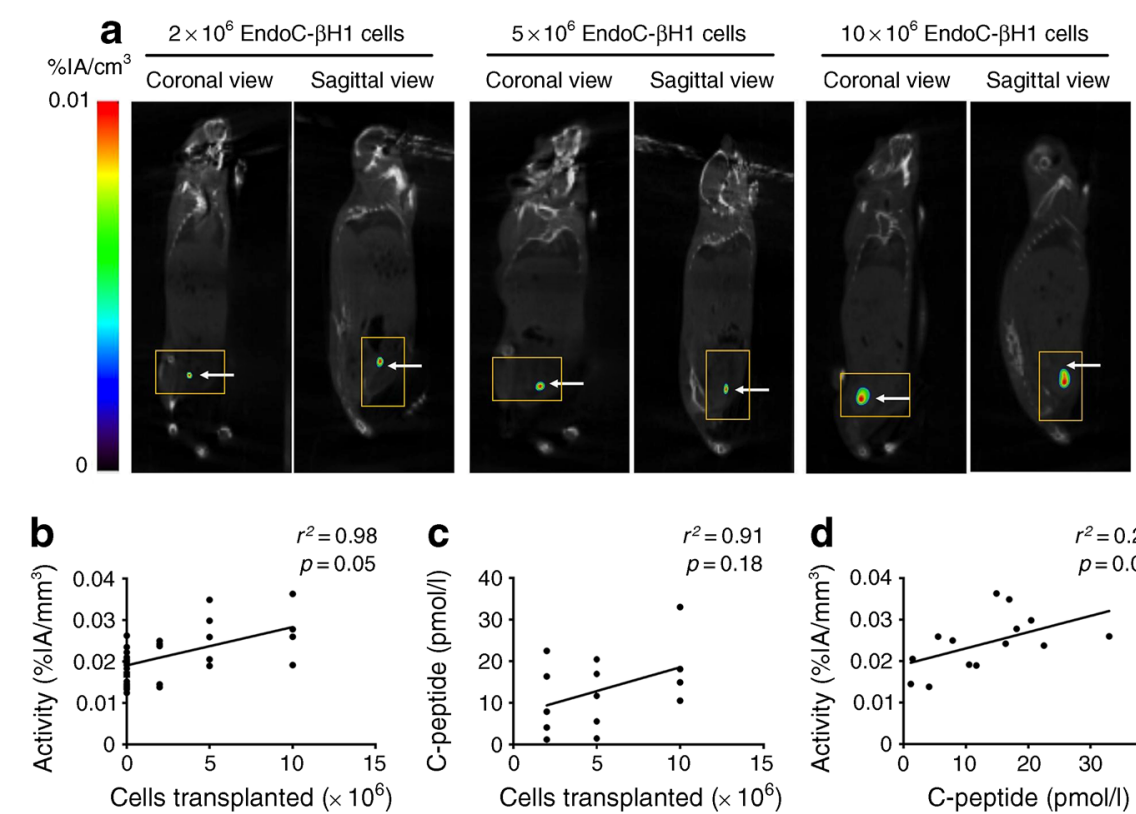

Cells transplanted $\left(\times 10^{6}\right)$
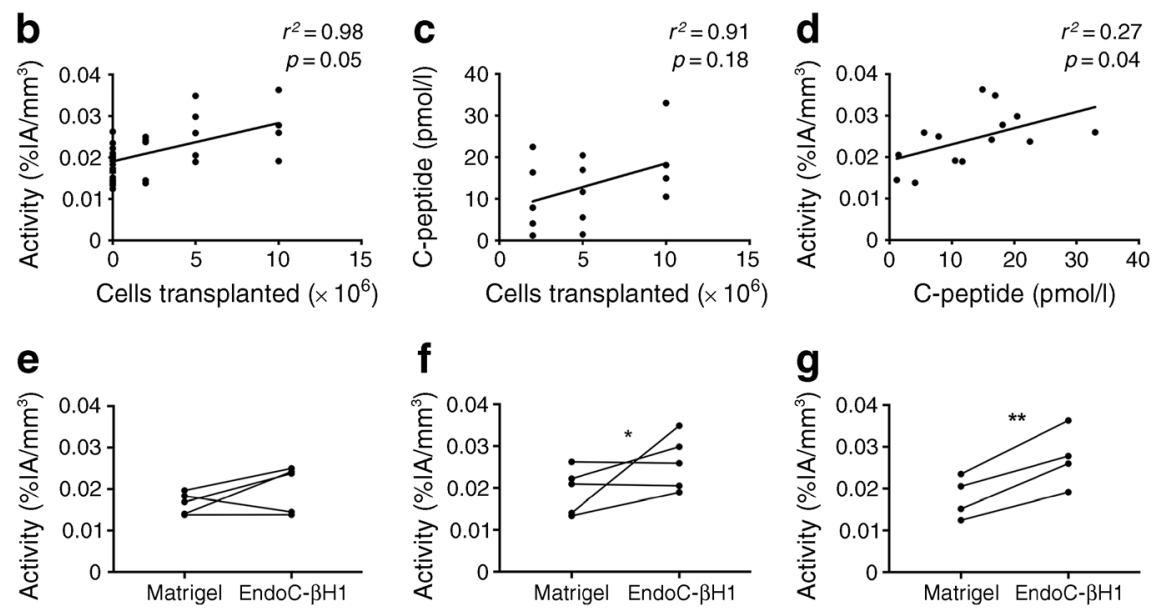

Fig. 2 Quantification by in vivo SPECT imaging of different quantities of EndoC- $\beta$ H1 cells transplanted in SCID mice. Female SCID mice were transplanted intramuscularly with different numbers of EndoC- $\beta \mathrm{H} 1$ cells $\left(2 \times 10^{6}, 5 \times 10^{6}\right.$ and $10 \times 10^{6}$ cells $)$ in Matrigel-containing rubber rings or, as a control, a ring containing Matrigel only. Twelve weeks posttransplantation, the mice were imaged by total-body CT followed by focal SPECT imaging based on the visualisation of the rubber ring on the CT scan and using the anti-DPP6 4hD29 nanobody. (a, b) Images were acquired $60 \mathrm{~min}$ post-injection of the contrast agent. The yellow square indicates the field-of-view of the SPECT camera; white arrows indicate graft localisation (a). The SPECT signal present in an ROI drawn around the rubber ring was quantified. Data are expressed as activity units (\%IA/

To calculate per cent of injected activity per $g$ of tissue (\% IA $/ g)$, we used the following formula:

$\% \mathrm{IA} / \mathrm{g}=\frac{\frac{\text { Organ radioactivity }}{\text { Injected dose }} \times 100}{\text { Tissue weight }}$

With: organ radioactivity in counts; injected dose in counts; tissue weight in $\mathrm{g}$; and per cent injected dose per $\mathrm{g}$ of tissue expressed as \%IA/g.

Animals were killed by cervical dislocation at $1.5 \mathrm{~h}$ postnanobody injection. Their organs were manually collected and washed once with PBS to remove residual blood. Organspecific radioactivity was measured against a standard of known activity with a gamma counter (Cobra II inspector 5003; Canberra-Packard, Schwadorf, Austria). Data are expressed as \%IA in the ROI $\left(\% \mathrm{IA} / \mathrm{mm}^{3}\right.$; in vivo imaging) $\mathrm{mm}^{3}$ in the ROI) (b). For $2 \times 10^{6}$ and $5 \times 10^{6}$ EndoC- $\beta$ H1 cells, $n=5$ mice; for $10 \times 10^{6}$ EndoC- $\beta$ H1 cells, $n=4$ mice; for Matrigel only, $n=15$ mice). (c, d) At the end of the imaging protocol, serum samples were collected and circulating human C-peptide was evaluated by ELISA assay. Data are expressed as pmol/1 human C-peptide $(n=4-5$ mice) (c). Linear regression between circulating human C-peptide values and radioactivity doses is shown (d). (e-g) Pairwise comparison between SPECT signal (expressed as $\% \mathrm{IA} / \mathrm{mm}^{3}$ in the ROI) measured in rings of mice grafted with $2 \times 10^{6}(\mathbf{e}), 5 \times 10^{6}(\mathbf{f})$ or $10 \times 10^{6}(\mathbf{g})$ EndoC- $\beta \mathrm{H} 1$ cells, and the corresponding control Matrigel rings ('Matrigel'). $* p \leq$ $0.05, * * p \leq 0.01$, paired Student's $t$ test

or as \% IA per $\mathrm{g}$ of tissue (\%IA/g; ex vivo dissection), corrected for decay and paravenous activity in the tail.

\section{PET imaging}

Details regarding PET imaging experiments are described in the ESM Methods. Briefly, $\left[{ }^{68} \mathrm{Ga}\right] 4 \mathrm{hD} 29$ imaging was performed on a preclinical PET/CT scanner (nanoScan PET/ CT with Nucline v2.01 [019.0000]; Mediso, Hungary). Animals were anaesthetised and intravenously injected with 2-4 MBq of the radiotracer. CT images were obtained for anatomical localisation, as well as for attenuation and scatter correction of PET images. PET images were acquired for $30 \mathrm{~min}$, starting $60 \mathrm{~min}$ post-injection, and reconstructed using a three-dimensional ordered subsets expectation maximisation (3D-OSEM) algorithm. All PET images were 

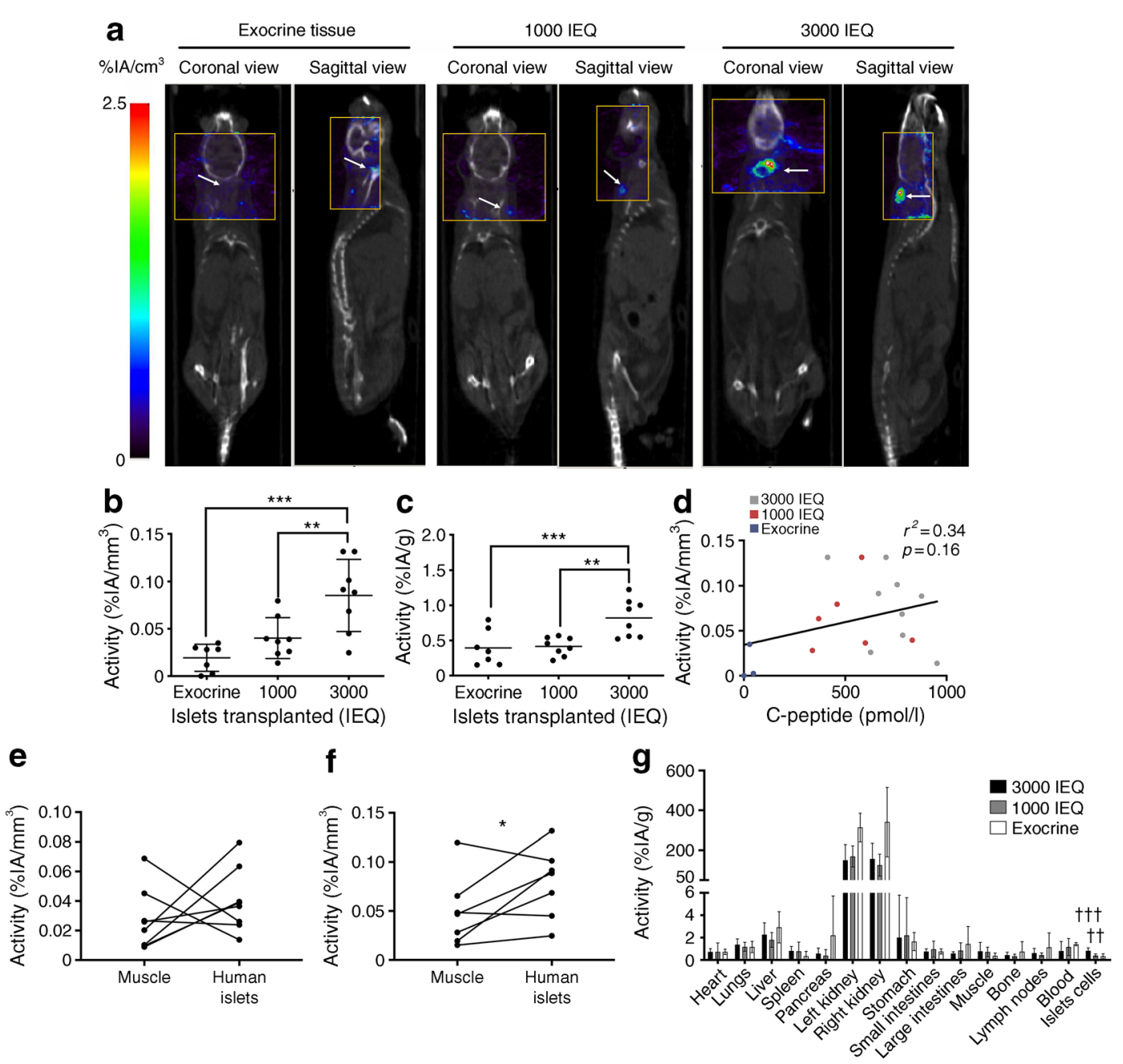

Fig.3 Quantification by in vivo SPECT imaging of different quantities of primary human islets transplanted into SCID mice. Female SCID mice were transplanted subcutaneously in the intrascapular area with different numbers of primary human islets (1000 or 3000 IEQ). As a negative control, a comparable volume of pancreatic exocrine tissue was similarly transplanted. Four weeks post-transplantation, the mice were imaged by total body CT, followed by a focal SPECT imaging scan using the antiDPP6 4hD29 nanobody. (a, b) Images were acquired $60 \mathrm{~min}$ post-injection of the contrast agent. The yellow square indicates the field-of-view of the SPECT camera; white arrows indicate the graft localisation (a). The SPECT signal present in the ROI (drawn around the intrascapular region) was quantified. Data are expressed as activity units $\left(\% / \mathrm{IA} / \mathrm{mm}^{3}\right.$ in the $\mathrm{ROI}$ ) and are presented as mean $\pm \mathrm{SEM} ; n=7-8$ mice per group. Linear regression analysis of number of islets transplanted vs activity (\%IA/ $\mathrm{mm}^{3}$ ) was also conducted (not shown); $r^{2}=0.99, p=0.02$ (b). (c) At

corrected for random counts, dead time and decay. Quantitative analysis was performed using the VivoQuant software v3.5 (InVicro, Boston, MA, USA). Different ROIs were designed around the tumour, liver and kidneys to measure radioactivity uptake in these organs. For tumour segmentation, the design of the ROI was performed based on the $\mathrm{CT}$ and encompassed the whole tumour volume. Segmentation of kidneys was performed based on the PET signal using the Otsu automatic thresholding method the end of the imaging session, the grafts were excised and radioactivity quantified using a gamma counter. Data are expressed as \%/IA per g of graft and are presented as mean $\pm \operatorname{SEM}(n=7-8$ mice per group) (linear regression: $r^{2}=0.96, p=0.12$ ). (d) Linear regression between circulating human C-peptide values and radioactivity doses is shown. (e, f) Pairwise comparison between SPECT signals (expressed as \%IA $/ \mathrm{mm}^{3}$ in the ROI) measured in the human islet graft (1000 IEQ, e; 3000 IEQ, f) and muscle (used as a negative control). (g) At the end of the imaging protocol, animals were killed and major organs collected. The radioactivity accumulated was quantified using a gamma counter. Data are expressed as mean \pm SEM activity units (\%/IA per g of graft); $n=7-8$ mice per group). $* p \leq 0.05$, paired Student's $t$ test; $* * p \leq 0.01, * * * p \leq 0.001$, ANOVA followed by Student's $t$ test with Š́dák correction; ${ }^{\dagger \dagger} p \leq 0.01$, islet cells after 1000 IEQ vs exocrine tissue transplantation; ${ }^{\dagger \dagger} p \leq 0.001$, islet cells after 3000 IEQ vs exocrine tissue transplantation

(VivoQuant v3.5), whereas spheres were designed in the liver. A spherical ROI was also drawn in the leg muscle and was used to calculate the radioactive background within the animal.

\section{Statistical analyses}

Data are presented as means \pm SEM. Analyses were performed using ANOVA followed by Student's $t$ test with Šídák 

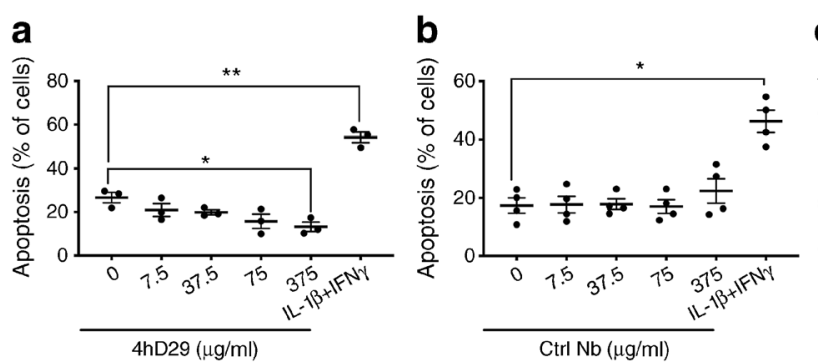

C

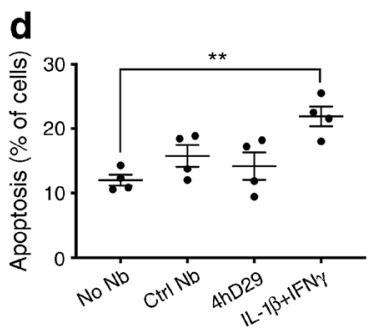

Fig. 4 Effect of the anti-DPP6 nanobody 4hD29 on apoptosis and insulin secretion in EndoC- $\beta \mathrm{H} 1$ cells and human islets. (a, b) EndoC$\beta \mathrm{H} 1$ cells were exposed to different concentrations $(7.5,37.5,75$ and $375 \mu \mathrm{g} / \mathrm{ml}$ ) of 4hD29 anti-DPP6 (a) or a control non-targeting nanobody (b) for $24 \mathrm{~h}$. As a positive control for apoptosis induction, cells were also exposed for $24 \mathrm{~h}$ to IL-1 $\beta(50 \mathrm{U} / \mathrm{ml})+\mathrm{IFN} \gamma(1000 \mathrm{U} / \mathrm{ml})$. At the end of the culture period, apoptosis was determined by Hoechst and propidium iodide staining. Data are expressed as percentages of apoptotic cells. (c) Glucose-stimulated insulin secretion was quantified by ELISA in EndoC$\beta \mathrm{H} 1$ cells that were not exposed to glucose $(0 \mathrm{G})$, or exposed to $20 \mathrm{mmol} / \mathrm{l}$ glucose (20G) and $20 \mathrm{mmol} / \mathrm{l}$ glucose $+20 \mu \mathrm{mol} / \mathrm{l}$ forskolin $(20 \mathrm{G}+\mathrm{FK})$

correction, or paired or unpaired Student's $t$ test, using GraphPad Prism 7 software (GraphPad Software, La Jolla, CA, USA). A $p$ value $\leq 0.05$ was considered as significant. All the statistical tests used were two-sided. Each experiment was performed on independent samples. No sample was excluded during the analysis. None of the experimenters was blind to group assignment and outcome assessment.

\section{Results}

To confirm that DPP6 protein expression is specific to human pancreatic islets (this has only been previously evaluated at the mRNA level [4]), we used human tissue arrays containing ten different tissues (pancreas, liver, lungs, prostate, spleen, kidney, stomach, brain white matter, intestine [colon] and brain cortex) isolated from five healthy individuals. DPP6 was expressed in the pancreatic islets of Langerhans but not in the other tissues tested, with the exception of some limited areas of the brain white matter and cortex (Fig. 1a,b). DPP6 expression was co-localised with both insulin and glucagon (Fig. 1b), confirming our previous findings [4]. Of note, data from the Human Protein Atlas project $[12,13]$ indicated strong DPP6 expression in the brain cortex, while we observed only limited expression in this tissue. This discrepancy may be due to the use of different primary antibodies (the

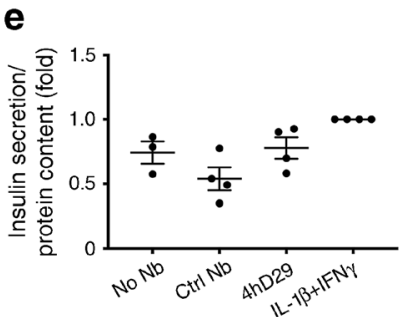

and no nanobody, $375 \mu \mathrm{g} / \mathrm{ml}$ control nanobody or $375 \mu \mathrm{g} / \mathrm{ml} 4 \mathrm{hD} 29$. Data are expressed as secreted insulin normalised for the total protein content (fold variation). (d, e) Apoptosis (d) and basal insulin secretion (e) were measured in dispersed human islets that were not exposed to nanobody or exposed to $375 \mu \mathrm{g} / \mathrm{ml}$ control nanobody or $375 \mu \mathrm{g} / \mathrm{ml}$ $4 \mathrm{hD} 29$ for $24 \mathrm{~h}$. Data are expressed as percentages of apoptotic cells (d) or secreted insulin normalised for the total protein content (fold variation) (e). The data represent the mean \pm SEM of 3-4 independent experiments. * $p \leq 0.05, * * p \leq 0.01$, ANOVA followed by Student's $t$ test with Š́dák correction. Ctrl, control; Nb, nanobody

Human Protein Atlas' antibody HPA050509 vs R\&D System's MAB2360 [Minneapolis, MN, USA] used in our studies) and/or the relatively small size of tissues used in the tissue microarrays.

We next evaluated whether there was a positive correlation between the SPECT signal emitted by ${ }^{99 \mathrm{~m}} \mathrm{Tc}$-labelled $4 \mathrm{hD} 29$ and the number of EndoC- $\beta \mathrm{H} 1$ cells or primary human islets grafted into immunodeficient SCID mice. The mice were initially transplanted intramuscularly with different amounts of EndoC- $\beta \mathrm{H} 1$ cells $\left(2 \times 10^{6}, 5 \times 10^{6}\right.$ and $10 \times 10^{6}$ cells). SPECT imaging of the mice indicated a clear increase in the signal with the increased number of implanted cells (Fig. 2a). Importantly, there was a positive correlation $\left(r^{2}=0.98, p=0.05\right)$ between the number of cells transplanted and the SPECT signal (Fig. 2b). The Cpeptide level at week 12 was also positively (but nonsignificantly) correlated with cell number (Fig. 2c) and with the SPECT signal (significantly, although to a lower level) (Fig. 2d). As previously described [4], a ring containing Matrigel only was implanted in the opposite limb of the mice as a negative control. When compared on a paired basis, the activity in the corresponding control rings was below the values observed in the EndoC- $\beta \mathrm{H} 1$ cell-containing rings (Fig. 2e-g), confirming the specificity of the signal. However, a significant increased uptake was only detectable in mice grafted with at least $5 \times 10^{6}$ 

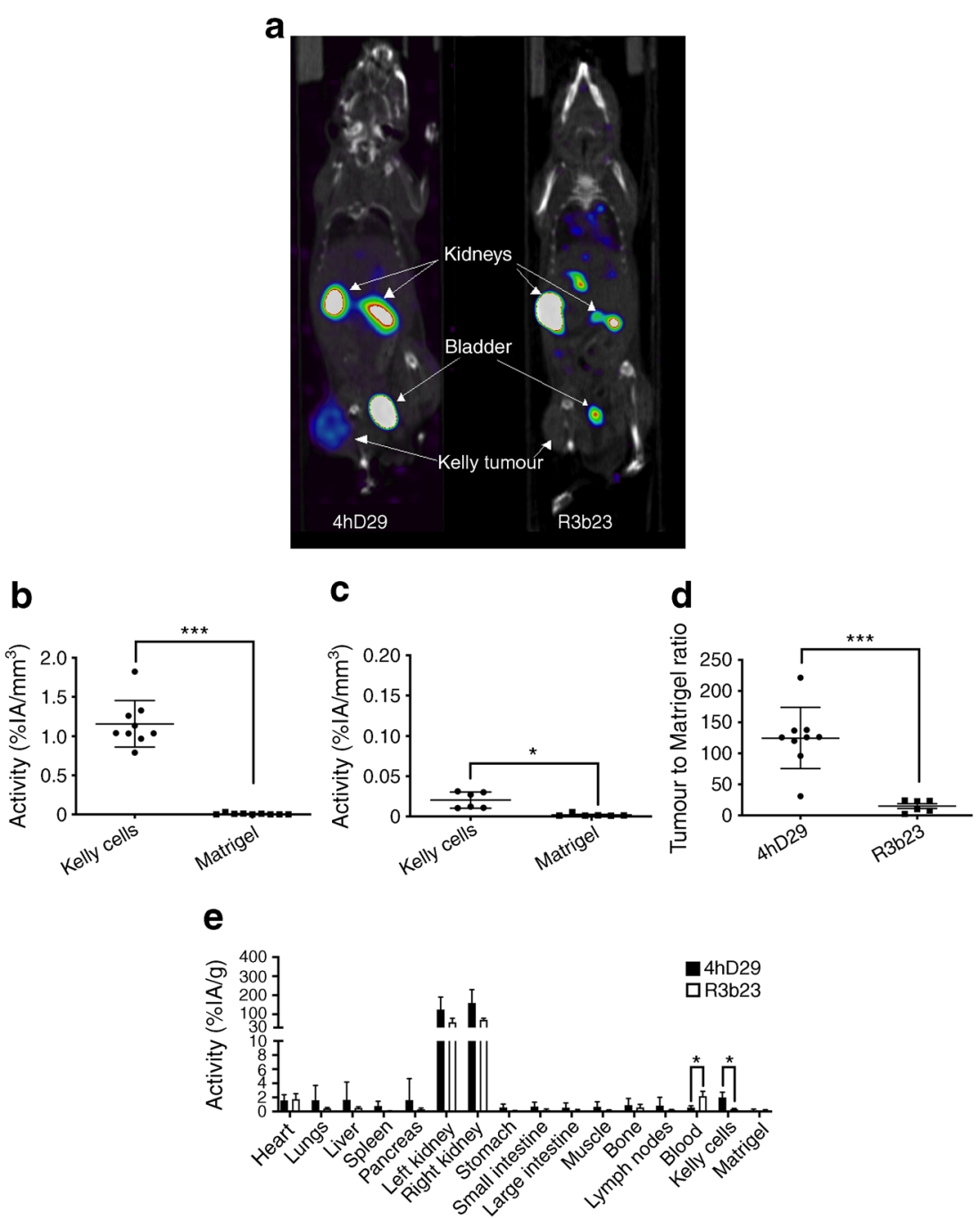

Fig. 5 Detection of Kelly neuroblastoma cells implanted in SCID by SPECT-CT using ${ }^{67}$ Ga-labelled anti-DPP6 4hD29 nanobody. Female SCID mice were transplanted subcutaneously with neuroblastoma Kelly cells $\left(5 \times 10^{6}\right.$ cells) or Matrigel (control). Four weeks post-transplantation, the mice were imaged by a full-body CT scan followed by SPECT imaging using ${ }^{67} \mathrm{Ga}$-labelled $4 \mathrm{hD} 29$ or non-targeting control nanobody (R3b23). (a-c) Images were acquired 60 min post-injection of the contrast agent (a). The SPECT signal in the tumour generated with $4 \mathrm{hD} 29$ (b) or control nanobody (c) was quantified. Data are expressed

cells (Fig. 2f, g), indicating the limited sensitivity of the method.

We next performed SPECT analysis of mice transplanted subcutaneously with different amounts of primary human islets (1000 or 3000 IEQ) or, as a negative control, with an equivalent volume of pancreatic exocrine tissue (Fig. 3a). There was a close positive correlation between the number of islets implanted and the SPECT signal (Fig. $3 b ; r^{2}=0.99$, $p=0.02$, data not shown). Quantification of the radioactivity in the retrieved grafts also showed a positive correlation between the signal obtained and the number of islets (Fig. $3 \mathrm{c})$. On the other hand, and similar to the results we obtained using EndoC- $\beta \mathrm{H} 1$ cells, the correlation between the SPECT as mean \pm SEM activity (\% IA $/ \mathrm{mm}^{3}$ in the ROI); $n=6-9$ mice. (d) Ratio between probe uptake in the tumour and Matrigel was calculated for $4 \mathrm{hD} 29$ and the control nanobody. (e) At the end of the imaging protocol, animals were killed and the major organs were collected. The radioactivity accumulated with 4hD29 (black bars) and the control nanobody (white bars) was quantified using a gamma counter. Data are expressed as mean \pm SEM activity units (\%/IA per $\mathrm{g}$ of graft); $n=6-9$ mice. ${ }^{*} p<0.05$, $* * * p<0.001$, paired $(\mathbf{b}, \mathbf{c})$ or unpaired $(\mathbf{d}, \mathbf{e})$ Student's $t$ test

signal and C-peptide levels was limited $\left(r^{2}=0.34\right.$; Fig. 3d). These results indicate that the imaging values obtained with our tracer provide a closer estimation of actual beta cell mass as compared with C-peptide determination.

In general, the SPECT signal in islet grafts was higher than in muscle (used as a control tissue; pairwise comparison; Fig. $3 \mathrm{e}, \mathrm{f})$. However, as for EndoC- $\beta \mathrm{H} 1$ cells, only mice grafted with 3000 IEQ islets showed a significant uptake in the graft as compared with muscle (Fig. 3f).

Distribution of $4 \mathrm{hD} 29$ nanobody was measured in the different organs of mice transplanted with 1000 or 3000 IEQ (primary human islets) or exocrine tissue (control); no significant difference was observed between the two groups, except 

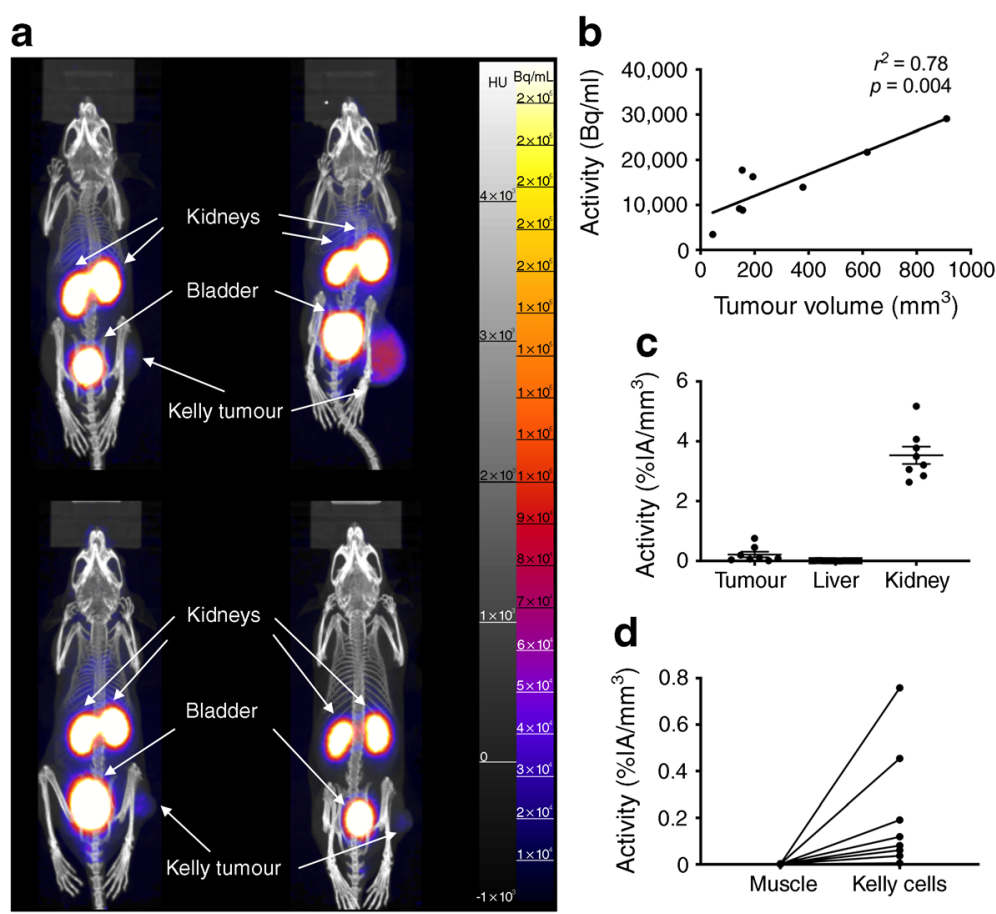

Fig. 6 Detection of Kelly neuroblastoma tumour cells implanted in SCID mice by PET/CT using $\left[{ }^{68} \mathrm{Ga}\right]$ NCS-NOTA-labelled $4 \mathrm{hD} 29$ antiDPP6 nanobody. Female SCID mice were transplanted subcutaneously with neuroblastoma Kelly cells $\left(5 \times 10^{6}\right.$ cells). Four weeks post-transplantation the mice harboured tumours of different sizes and were imaged by a full-body CT scan followed by PET imaging using $\left[{ }^{68} \mathrm{Ga}\right] \mathrm{NCS}$ NOTA-labelled 4hD29. (a, b) Images were acquired 60 min post- injection of the contrast agent (a). The PET signal present in the tumour was quantified (the ROI was drawn based on the CT picture). Data are expressed as $\mathrm{Bq} / \mathrm{ml}$ and plotted against the tumour volume determined by CT; $n=8$ mice (b). (c) PET signal (expressed as $\% \mathrm{IA} / \mathrm{mm}^{3}$ in the ROI) was quantified in ROIs drawn around the tumour, liver and kidneys. (d) Pairwise comparison of the signal measured in the ROIs drawn around the graft or muscle ( $n=8$ mice). HU, Hounsfield units a higher signal in the grafts (islet cells) of the mice implanted with 3000 IEQ vs 1000 IEQ or the exocrine tissue $(p=0.01$; Fig. 3g). The biodistribution of $4 \mathrm{hD} 29$ observed in mice grafted with human islets was similar to that previously observed in mice transplanted with EndoC- $\beta \mathrm{H} 1$ cells [4].

In order to use the anti-DPP6 4hD29 nanobody for future human in vivo imaging, it is crucial to exclude toxicity against human beta cells. Dose-response studies performed on EndoC- $\beta \mathrm{H} 1$ cells did not show any evidence of $4 \mathrm{hD} 29$ induced apoptosis (Fig. 4a,b), even when the cells were exposed for $24 \mathrm{~h}$ to a $4 \mathrm{hD} 29$ concentration 50 times higher than those reached in vivo $(\sim 7.5 \mu \mathrm{g} / \mathrm{ml})$. Proinflammatory cytokines (IL-1 $\beta+$ IFN $\gamma$ ) were used as a positive control and induced, as expected, a 2-3-fold increase in human beta cell apoptosis vs control (Fig. 4a,b). Partial protection against apoptosis was observed in EndoC- $\beta \mathrm{H} 1$ cells treated with $375 \mu \mathrm{g} / \mathrm{ml} 4 \mathrm{hD} 29$ (Fig. 4a), but this was not confirmed in primary human islets (Fig. 4d). The nanobodies did not have a significant toxic effect in dispersed islet cells (Fig. 4d). Neither 4hD29, nor a non-targeting control nanobody, affected glucose-stimulated insulin secretion in EndoC- $\beta \mathrm{H} 1$ cells or insulin accumulation in the medium of primary human islet cultures (Fig. 4c,e). As a whole, these findings indicate that a prolonged $(24 \mathrm{~h})$ exposure of human beta cells to high concentrations of the anti-DPP6 nanobody 4hD29 does not induce any significant toxicity or dysfunction in human beta cells. Considering that use of this nanobody for eventual in vivo imaging will require 50 times lower concentrations and much shorter periods of exposure, it is unlikely that it will harm human beta cell survival or function.

Future use of 4hD29 for a first-in-man trial must rely on a probe that can be used for PET imaging, a more sensitive technique than SPECT [14]. This should hopefully allow us to obtain a better resolution than that obtained in the SPECT experiments in this study, which were successful to discriminate between 3000 IEQ and exocrine tissue (negative control) grafted into SCID mice but failed to detect clear differences between 1000 IEQ and exocrine tissue (Fig. 3b,c). We, thus, decided to adapt the anti-DPP6 4hD29 nanobody for PET imaging. The first step was the conjugation of the nanobody to a chelator suitable for PET radioisotopes, NCS-NOTA. We next tested whether the addition of the NCS-NOTA group changed the specificity or the sensitivity of $4 \mathrm{hD} 29$. To this purpose, the nanobody was radiolabelled with ${ }^{67} \mathrm{Ga}$ and mice grafted with $5 \times 10^{6}$ Kelly cells (neuroblastoma cells positive for DPP6) were imaged by SPECT (Fig. 5a); labelled nontargeting nanobody (R3b23) was used as a control. Quantification showed that $4 \mathrm{hD} 29$ accumulated 15 -fold more 
in the tumours, as compared with the non-targeting nanobody (Fig. 5b-d). When compared with the R3b23 control nanobody, ex vivo biodistribution analysis confirmed that the $4 \mathrm{hD} 29$ nanobody accumulates specifically in the tumour (Kelly cells), with limited uptake in other organs, except in the kidneys due to the renal clearance of the nanobodies (Fig. 5e). The blood uptake of the $4 \mathrm{hD} 29$ nanobody was lower compared to R3b23 control nanobody (Fig. 5e). These biodistribution data are in accordance with our previous results obtained in SCID mice transplanted with the same cells [4], suggesting that addition of the NCS-NOTA group did not change the specificity of the $4 \mathrm{hD} 29$ nanobody.

Based on these encouraging results, we performed a proofof-concept experiment of PET imaging on SCID mice grafted with $5 \times 10^{6}$ Kelly neuroblastoma cells. Four weeks after grafting, tumours of different volumes were obtained. The mice were then imaged using $\left[{ }^{68} \mathrm{Ga}\right]$ NCS-NOTA-labelled $4 \mathrm{hD} 29$ nanobody and PET/CT. There was a clear accumulation of the radiolabelled probe in the tumour (Fig. 6a) and, importantly, a positive correlation $\left(r^{2}=0.78, p=0.004\right)$ was observed between the tumour volume and the PET signal (Fig. $6 b)$. Quantification of the radioactivity accumulated in the ROIs drawn around the graft, the kidneys and the liver, based on the CT scan, confirmed that $\left[{ }^{68} \mathrm{Ga}\right] \mathrm{NCS}-\mathrm{NOTA}$-labelled 4hD29 nanobody accumulates specifically in the graft (Fig. 6c). Pairwise comparisons between the signals measured in muscle and in the grafts confirmed that these results were not due to a variable non-specific accumulation of the radiotracer (Fig. 6d).

\section{Discussion}

Here, we show that the DPP6 protein is mainly expressed in human pancreatic islets, as compared with other closely located tissues. We used an anti-DPP6 nanobody, 4hD29, to image both human EndoC- $\beta \mathrm{H} 1$ cells and primary human islets engrafted in immunodeficient mice. We observed a significant correlation between the SPECT signal emitted by ${ }^{99 \mathrm{~m}} \mathrm{Tc}$ radiolabelled 4hD29 nanobody and the number of EndoC- $\beta \mathrm{H} 1$ cells or primary human islets implanted into mice. This, and the observation that $4 \mathrm{hD} 29$ is not toxic to human beta cells, opens the door for the future use of this tracer for in vivo quantification of pancreatic islet grafts or endogenous endocrine cells in humans. With regard to the imaging of islets, clear differences in SPECT signals were only obtained with the highest number of cells implanted; so, 4hD29 imaging needs further improvement. Clinically, in vivo human islet imaging must rely on PET, a more sensitive technique than clinical SPECT [14]. For this purpose, we adapted $4 \mathrm{hD} 29$ for PET/CT by conjugation to NCS-NOTA. This did not alter specificity of the nanobody, and proof-ofprinciple experiments using Kelly cells, a neuronal cell line that expresses DPP6 to a similar level to that in human beta cells, showed that this technique has excellent sensitivity.

Since the $4 \mathrm{hD} 29$ nanobody recognises human, but not mouse or rat, DPP6, the present study was based on imaging of human beta cells grafted in mice. Importantly, these models rely on the transplantation of a relatively high number of cells in a small volume $\left(2-10 \times 10^{6}\right.$ EndoC- $\beta$ H1 cells; $1000-3000$ human IEQ). Thus, the positive observations in this study do not guarantee that similar results will be obtained when imaging endogenous islets that are scattered throughout the pancreas in humans. In an attempt to increase the chances of success in future first-in-man studies, we successfully adapted the 4hD29 nanobody for PET imaging.

The fact that DPP6 is expressed in both beta and alpha cells [4] is a limitation that may affect quantification of the human endogenous beta cell mass using the $4 \mathrm{hD} 29$ nanobody. Recent findings suggest the presence of alpha cell dysfunction in individuals with type 1 diabetes [15], and RNA sequencing analysis of islets from two individuals with type 1 diabetes indicated a very low expression of DPP6 $(<0.5$ reads per $\mathrm{kb}$ per million mapped reads [RPKM]) as compared with islets from non-diabetic individuals (30 RPKM) [16], indicating a global decrease in islet DPP6 expression in type 1 diabetes. There are presently no available tracers that bind exclusively to human beta cells and, until such a tracer is discovered, targeting DPP6 will remain a potentially useful approach for in vivo islet cell imaging.

Acknowledgements We thank the following individuals for their excellent technical support: C. Peleman (In Vivo Cellular and Molecular Imaging Laboratory [ICMI], Vrije Universiteit Brussel [VUB], Brussels, Belgium); A. Musuaya, N. Pachera and M. Pangerl (ULB Center for Diabetes Research, Université Libre de Bruxelles [ULB], Brussels, Belgium); and C. De Maeseneire, G. Doumont, S. Lacroix, N. Passon and G. Vansimaeys (Center for Microscopy and Molecular Imaging [CMMI], Gosselies, Belgium). We are grateful to the two anonymous referees for their insightful and very useful suggestions to improve the present study.

Data availability All data generated or analysed during this study are included in this manuscript.

Funding This work was supported by grants from the JDRF (3-2-SRA2017-432-S-B) to DLE and ND. DLE was also funded by Walloon Excellence in Lifesciences and biotechnology-Fonds de la Recherche Fondamentale Stratégique (Welbio-FRFS), European Union (Horizon 2020 Project T2D Systems), Brussels Region (INNOVIRIS BRIDGE grant DiaType) and the Fonds National de la Recherche Scientifique (FNRS, Belgium). The Center for Microscopy and Molecular Imaging (CMMI) consortium is supported by the European Regional Development Fund, the Walloon Region and the Fonds Erasme (convention AVN). DLE and PM have received funding from the Innovative Medicines Initiative 2 Joint Undertaking under grant agreement No 115797 (INNODIA). This Joint Undertaking receives support from the Union's Horizon 2020 research and innovation program and the EFPIA, JDRF and The Leona M. and Harry B. Helmsley Charitable Trust. DLE and ND are members of the Brussels Diabetes Research Pole, an initiative supported by the universities ULB and VUB. FP and JK-C were funded by European Genomic Institute for Diabetes (ANR-10-LABEX-46 to FP) 
and the European Consortium for Islet Transplantation funded by the JDRF International (JDRF award 31-2008-416).

Duality of interest DLE and ND hold a patent related to the use of DPP6 and $4 \mathrm{hD} 29$ nanobody for in vivo beta cell imaging. The other authors declare that there is no duality of interest associated with this manuscript.

Contribution statement The study was conceptualised by SD, RGR, ND and DLE. The funding was acquired by ND and DLE. Experiments were performed by SD, RGR and JT. The methodology used was defined by SD, RGR, LM, FP, JK-C, ND and DLE. SD and DLE were in charge of the project administration. LM, PM, FP, JK-C, ND and DLE provided resources (human islets and mice). The project was supervised by ND and DLE. The original draft of this manuscript was written by SD, RGR and DLE. All the authors were involved in the data analysis and editing the manuscript and approved the final version of the manuscript. SD is responsible for the integrity of the work as a whole.

\section{References}

1. Gotthardt M, Eizirik DL, Aanstoot HJ et al (2018) Detection and quantification of beta cells by PET imaging: why clinical implementation has never been closer. Diabetologia 61(12):2516-2519. https://doi.org/10.1007/s00125-018-4745-5

2. Andralojc K, Srinivas M, Brom M et al (2012) Obstacles on the way to the clinical visualisation of beta cells: looking for the Aeneas of molecular imaging to navigate between Scylla and Charybdis. Diabetologia 55(5):1247-1257. https://doi.org/10.1007/s00125012-2491-7

3. Brom M, Joosten L, Frielink C et al (2018) Validation of 111 inexendin SPECT for the determination of the beta cell mass in biobreeding diabetes prone rats. Diabetes 67(10):2012-2018. https://doi.org/10.2337/db17-1312

4. Balhuizen A, Massa S, Mathijs I et al (2017) A nanobody-based tracer targeting DPP6 for non-invasive imaging of human pancreatic endocrine cells. Sci Rep 7(1):15130. https://doi.org/10.1038/ s41598-017-15417-2

5. Marchetti P, Suleiman M, Marselli L (2018) Organ donor pancreases for the study of human islet cell histology and pathophysiology: a precious and valuable resource. Diabetologia 61(4): 770-774. https://doi.org/10.1007/s00125-018-4546-x
6. Kerr-Conte J, Vandewalle B, Moerman E et al (2010) Upgrading pretransplant human islet culture technology requires human serum combined with media renewal. Transplantation 89(9):1154-1160. https://doi.org/10.1097/TP.0b013e3181d154ac

7. Ravassard P, Hazhouz Y, Pechberty S et al (2011) A genetically engineered human pancreatic $\beta$ cell line exhibiting glucoseinducible insulin secretion. J Clin Invest 121(9):3589-3597. https://doi.org/10.1172/JCI58447

8. Brozzi F, Nardelli TR, Lopes M et al (2015) Cytokines induce endoplasmic reticulum stress in human, rat and mouse beta cells via different mechanisms. Diabetologia 58(10):2307-2316. https:// doi.org/10.1007/s00125-015-3669-6

9. Cnop M, Ladriere L, Hekerman P et al (2007) Selective inhibition of eukaryotic translation initiation factor 2 alpha dephosphorylation potentiates fatty acid-induced endoplasmic reticulum stress and causes pancreatic beta-cell dysfunction and apoptosis. J Biol Chem 282(6):3989-3997. https://doi.org/10.1074/jbc. M607627200

10. Juan-Mateu J, Alvelos MI, Turatsinze JV et al (2018) SRp55 regulates a splicing network that controls human pancreatic $\beta$-cell function and survival. Diabetes 67(3):423-436. https://doi.org/10.2337/ db17-0736

11. Loening AM, Gambhir SS (2003) AMIDE: a free software tool for multimodality medical image analysis. Mol Imaging 2(3):131-137. https://doi.org/10.1162/153535003322556877

12. Uhlen M, Zhang C, Lee S et al (2017) A pathology atlas of the human cancer transcriptome. Science 357(6352):eaan2507. https:// doi.org/10.1126/science.aan2507

13. The Human Protein Atlas. Available from www.proteinatlas.org/ ENSG00000130226-DPP6/tissue. Accessed 15 July 2019

14. Rahmim A, Zaidi H (2008) PET versus SPECT: strengths, limitations and challenges. Nucl Med Commun 29(3):193-207. https:// doi.org/10.1097/MNM.0b013e3282f3a515

15. Brissova M, Haliyur R, Saunders D et al (2018) $\alpha$ Cell function and gene expression are compromised in type 1 diabetes. Cell Rep 22(10):2667-2676. https://doi.org/10.1016/j.celrep.2018.02.032

16. Mastracci TL, Turatsinze JV, Book BK et al (2018) Distinct gene expression pathways in islets from individuals with short- and longduration type 1 diabetes. Diabetes Obes Metab 20(8):1859-1867. https://doi.org/10.1111/dom.13298

Publisher's note Springer Nature remains neutral with regard to jurisdictional claims in published maps and institutional affiliations. 